\title{
ICTS AND MOBILE APPLICATIONS FOR PROMOTING TOURISM DESTINATIONS: THE CASE OF SMART MARCA APP.
}

\author{
Concetta Ferrara \\ Roberto Pierdicca \\ Mattia Balestra \\ Chiara Mignani \\ Emanuele Frontoni \\ Alessio Cavicchi
}

https://doi.org//10.20867/tosee.06.16

\begin{abstract}
Purpose - In last decades, digital technologies have progressively transformed tourism becoming an opportunity to satisfy the demand for cultural tourism, increasingly asking for immersive and interactive experiences. This paper investigates the connections among tourism, cultural heritage, and ICT, by providing an assessment of how these applications can influence customers' intentions to visit a destination. To this aim, the case of Smart Marca - a mobile tourism app aimed at promoting cultural tourism in Fermo area (Marche Region, Italy)- is presented.

Methodology - The Technology Acceptance Model (TAM) has been adopted as a framework to explore customer intentions to adopt tourism apps and visit a destination. A survey on a sample of 128 university students has been conducted. Starting from the TAM framework elaborated by Kuo and colleagues (2019), a grid of 8 influencing factors has been built, in order to investigate young users' attitudes towards continuing using the app, adopting other similar mobile apps and visiting one or more of the attractions presented within the app.

Findings - The survey found that perceived usefulness and perceived ease of use play major roles on attitudes towards continuing to use Smart Marca and adopting other similar applications. Results also show that specific features of a mobile app can positively affect the intention to visit a destination.

Contribution - The research highlights that new technologies, and mobile apps, could play a crucial role for the promotion of a destination. Results may be also useful in terms of marketing, to increase the ability of the mobile app to attract tourists.

Keywords: ICT, e-tourism, mobile tourism app, Technology Acceptance Model (TAM), cultural tourism, experiential tourism.
\end{abstract}

\section{INTRODUCTION}

In 2013, the McKinsey Global Institute identified a set of 12 disruptive technologies predicted to have significant potential to drive economic impact by 2025 (Manyika et al. 2013). Among these, Information Communications Technology (ICT) was expected to impact some areas of tourism too. The application of ICT to tourism, namely e-tourism, has been in existence for over 30 years, starting with the spread of the internet and the introduction of central reservation and booking systems and progressively transforming tourism (Shanker 2008; Buhalis and O'Connor 2015; Buhalis and Jun 2011). E-tourism represents an opportunity to satisfy the demand for cultural tourism, which increasingly 
ToSEE - Tourism in Southern and Eastern Europe, Vol. 6, pp. 229-245, 2021.

C. Ferrara et al.: ICTS AND MOBILE APPLICATIONS FOR PROMOTING TOURISM ...

requires a re-evaluation of the original role of cultural attractions towards immersive and interactive experiences, giving the opportunity to taste local and authentic culture (Richards 2011; 2014). Indeed, many studies, demonstrate that new technologies enhance how culture is experienced, both in terms of number of people who can have access to knowledge and quality of the diffusion of the knowledge itself (Arcese et al. 2011; Haydar et al. 2011; Bekele et al. 2018).

Studies on e-tourism, mainly focused on the use of the internet (Fodor and Werthner 2005; Cardoso and Lange 2007), and mobile applications in tourism services (Sebastia et al. 2009; García-Crespo et al. 2009; Smirnov et al. 2015). Within this field of studies, a gap concerns the analysis of the influence of mobile travel or tourism app on tourist behaviors. Indeed, few studies have evaluated the relationship between the adoption of mobile applications and the decision to visit a destination. Highlighting the dynamics and implications of this relationship may be useful to increase the ability of a mobile app to attract tourists in a certain destination.

To full fill this gap, the purpose of this paper is exploring the connections among tourism, cultural heritage, and digital technology, by answering to the following research questions:

RQ1: Which are the potentials of mobile tourism apps to promote a destination?

RQ2: To what extent mobile tourism apps can influence customers' intentions to experience a destination?

In the first part, a literature review on cultural heritage as a destination enhancer and on the role of e-tourism and current technologies for the promotion of cultural tourism is outlined; then the analysis moves to the adoption of e-tourism by consumers, by focusing on the Technology Acceptance Model (TAM). In the second part the case of Smart Marca - a mobile tourism app to promote experiential cultural tourism in Fermo area (Marche Region, Italy) is presented. Then the methodology is outlined, and results are discussed. Conclusions point out that mobile tourism apps, can play a crucial role in the selection and promotion of a destination. Understanding attitudes regarding user adoption of mobile tourism apps will contribute to suggest new possibilities to attract customers, new approaches to develop tourism marketing strategies and new ideas to enhance the customer experience.

\section{LITERATURE REVIEW}

\subsection{The role of cultural heritage as a destination enhancer}

Culture can play a dual role in tourism (Zeppel and Hall 1991). On the one hand, it can influence the desirability of a destination (Kumar 2017), by reinvigorating the interest in history and culture (Richards 2018), introducing tourists and local communities to the cultural roots of a territory (Kajos and Banyai 2012) and satisfying both the need of authenticity and the return to origins (Beverland and Farrekky 2010). On the other hand, cultural and heritage tourism is a tool of economic development that achieves economic growth, attracting visitors (Silberberg 1995; Csapo 2012). 
ToSEE - Tourism in Southern and Eastern Europe, Vol. 6, pp. 229-245, 2021.

C. Ferrara et al.: ICTS AND MOBILE APPLICATIONS FOR PROMOTING TOURISM ...

In recent decades, cultural and heritage tourism is experiencing an ongoing process of change, in response to the fragmentation of supply and demand, the growing competition between destinations and companies (McKercher and Du Cros 2002; Richards and Wilson 2007), and the definition of a new idea of culture. Indeed, cultural heritage is no longer associated to the sum of works of art, but includes landscape, intangible assets, and all «resources inherited from the past which people identify, independently of ownership, as a reflection and expression of their constantly evolving values, beliefs, knowledge and traditions» (Council of Europe 2015). Along with this shift of paradigm, tourists are increasingly looking for new, meaningful, and immersive experiences. To answer to these new needs, ICT could be applied to cultural and heritage tourism to prove lively experiences or re-create places and historical scenes, able to make a cultural destination more appealing to a prospective tourist.

\subsection{E-tourism and current technologies for cultural tourism}

In 2010, European Commission highlighted that innovation and new information technologies have become determining factors to stimulate competitiveness in the European tourism industry (European Commission 2010, 8). The relevance of this phenomenon is confirmed by data. In 2015, the $50 \%$ of Europeans who used the internet to shop online, bought or ordered online holiday accommodation, such as hotel reservation $(26 \%)$ and/or other travel arrangement (24\%) (Eurostat 2016). In this scenario, mobile communication devices play a crucial role: the $57 \%$ of all digital media usage comes from mobile apps for smartphones. This phenomenon is closely related to the user's age profile and affects more the generation $\mathrm{Z}(18-24)$ and millennials (25-40), with an average of 112,6 monthly hours per user for 18-24 age rank and 102,4 monthly hours per user for 25-34 (Blair 2019). In this context, tourism and travel app category represents the $5 \%$ of all online apps (Sommer 2015). According to TripAdvisor (2016), the $45 \%$ of connected travellers use mobile phones to plan and/or book travel activities: the $56 \%$ looks for restaurants, the $47 \%$ reads other users reviews and the $36 \%$ looks for accommodation.

The application of ICT to tourism, can make a tourism offer more attractive, inclusive, by reducing costs, since it provides tools for developing, managing, and distributing tourism products worldwide (Bethapudi 2013; Pierdicca et al. 2019). Thanks to ICT, the planning process is easier and more flexible (Meehan et al., 2016) and the travel experience is more engaging both during and after the trip (Rezaei et al. 2016). In this context, mobile devices play a crucial role, since they provide a real-time information support, by allowing tourists to access information, (Trakulmaykee et al. 2013); making decisions more effectively (Lamsfus et al. 2013) and living interactive experiences (Ukpabi and Karjaluoto, 2017). In these processes, context-awareness services enable a form of communication based on people geographical location (Hugues and Moscardo 2019) and transform places in "senseable spaces", by providing immersive experiences (Osaba et al. 2018) and facilitating interactions among tourists, local community and hosts. Moreover, the collection and analysis of digital footprints, allows to receive feedbacks about performances and understand tourists' behaviours (Zhang et al. 2010; Önder et al. 2016). 
ToSEE - Tourism in Southern and Eastern Europe, Vol. 6, pp. 229-245, 2021.

C. Ferrara et al.: ICTS AND MOBILE APPLICATIONS FOR PROMOTING TOURISM ...

Immersive reality technology, who includes all technologies and applications providing immersive experiences, bounded by real and virtual environments (Bekele et al. 2018; Bec et al. 2019; Bekele and Champion 2019), also plays a crucial role. AR and VR can make a place or a product immediately accessible in digital format, by displaying additional contents and involving users in an immersive cognitive process focused on edutainment and learning by consuming (Fritz et al. 2005; Pierdicca et al. 2015a; b; Bogicevic et al. 2019). Connecting the real world with virtually computer-generated data, by overlapping images and producing information in layers (Azuma et al, 2001), AR enables interactions with virtual objects (Liarokapis 2007) and increase tourists' awareness about a place. In this sense, it is a useful tool for interactively accessing location-based information about a point of interest and creating unique experiences. Moreover, it allows cultural institutions, tourist professionals and destinations to distinguish themselves (Kounavis et al. 2012). VR creates completely virtual environments and is a great support for researchers and tourism professionals, for cultural heritage management, marketing, entertainment, education, accessibility, and conservation (Guttentag 2010). VR application to heritage tourism allows to provide immersive and involving experiences, using artifacts and actions related to the past (Bec et al. 2019), although real experiences cannot be completely substitute (Mura et al. 2017). Table 1 provide some examples of apps and technologies who applied AR and VR to cultural heritage.

Table 1: Main apps and technologies applying $A R$ and VR for cultural heritage

\begin{tabular}{|c|c|c|c|}
\hline App & AR & VR & Description \\
\hline Aurasma $^{1}$ & $X$ & & $\begin{array}{l}\text { App providing additional multimedia contents when pointing } \\
\text { an object (newspapers; picture; image, etc.) with a smartphone } \\
\text { or a tablet. }\end{array}$ \\
\hline Virtuoso $^{2}$ & $\mathrm{X}$ & & $\begin{array}{l}\text { Educational game which allows to put in a chronological order } \\
\text { a collection of artworks. }\end{array}$ \\
\hline Explore! $!^{3}$ & $\mathrm{X}$ & & $\begin{array}{l}\text { Mobile augmented reality game supporting middle school } \\
\text { students in visiting Italian archaeological sites. }\end{array}$ \\
\hline $\begin{array}{l}\text { Google } \\
\text { Expeditions }\end{array}$ & & $\mathrm{X}$ & $\begin{array}{l}\text { App providing } 360^{\circ} \text { virtual visits to popular cultural } \\
\text { attractions through a smartphone and a Google Cardboard } \\
\text { viewer. }\end{array}$ \\
\hline Vatican app ${ }^{5}$ & & $\mathrm{X}$ & $\begin{array}{l}\text { App providing } 360^{\circ} \text { virtual tours to Vatican rooms and } \\
\text { information about the site. }\end{array}$ \\
\hline Cave & & $\mathrm{X}$ & $\begin{array}{l}\text { App transforming surfaces in projection screens enabling, } \\
\text { through the use of } 3 \mathrm{D} \text { glasses, immersive experiences } \\
(\text { Creagh, 2003). }\end{array}$ \\
\hline
\end{tabular}

Source: authors 'elaboration

\footnotetext{
${ }^{1}$ https://aurasma.it.uptodown.com/android, viewed 19 May 2021.

${ }^{2} \mathrm{http}$ ://virtuosoapps.com/augmented-reality-virtuoso.html viewed 19 May 2021.

${ }^{3} \mathrm{https}: / /$ play.google.com/store/apps/details?id=io.motive.explorear\&hl=en_US\&gl=US viewed 19 May 2021.

${ }^{4} \mathrm{https}: / /$ edu.google.com/products/vr-ar/expeditions/?modal_active=none viewed 19 May 2021.

${ }^{5} \mathrm{http}: / /$ www.vatican.va/content/vatican/it/apps.html viewed 19 May 2021.
} 
ToSEE - Tourism in Southern and Eastern Europe, Vol. 6, pp. 229-245, 2021.

C. Ferrara et al.: ICTS AND MOBILE APPLICATIONS FOR PROMOTING TOURISM

\subsection{Consumers 'acceptance of e-tourism}

The existing literature on e-tourism focuses on consumers engagement in the use of ICT for tourism services, by considering consumers' behaviours regarding ICT (Steinbauer and Werthner 2007; Nunkoo and Ramkisson 2013; Sahli and Legoherel 2015) and consumers adoption of new technologies (Parra-López et al. 2011; Ukpabi and Karjaluoto 2016; Book and Tanford 2019). As for the influence of mobile information system in tourism, researchers focused on factors, affecting users' attitude towards adopting and using tourism apps to choose a destination, by covering various topics (No and Kim 2014; Lai 2015; Kim et al. 2015; Chang et al. 2016; Kuo et al. 2019).

As for models mostly applied to analyse users' behaviours and measure the level of technology acceptance within the tourism sector, existing studies mainly focused on the social cognitive theory (SCT) (Lu et al. 2015) the innovation diffusion theory (IDT) (Chang and Jang 2014), the technology acceptance model (TAM) (Huh et al. 2009; Kim et al. 2008; Kuo et al. 2019), the unified theory of acceptance and use of technology (UTAUT) (San Martín and Herrero 2012) and the extended unified theory of acceptance and use of technology (UTAUT 2) (Gupta et al. 2018). While SCT pays more attention to personal and environmental variables (Bandura 2001), IDT, UTAUT (and UTAUT 2) and TAM focus on the characteristics of technology that may affect behavioural intention, adoption decision and use behaviour.

The technology acceptance model (TAM) is an information systems theory elaborated by Davis (1985) and rooted in the theory of reasoned action (TRA), according to which a behaviour depends on the intention to perform that behaviour, which in turns is determined by the person's attitude and subjective norm concerning the behaviour in question (Fishbein et al. 1980). Starting from this theory, TAM assumes that perceived ease of use (PEU) (the degree to which a person believes that using a particular system will be free of effort) and perceived usefulness (PU) (the degree to which a person believes that using a particular system will enhance his or her performance), can predict the usage of technology, since they are primary determinants of user technology adaptation. According to the TAM, PEU and PU are influenced by external variables (Xia et al. 2018), and all determine users' intention (Davis 1985). TAM includes two other constructs: the attitude towards use, corresponding to user's evaluation of the desirability of employing a particular information systems application and the behavioural intention to use, that is a measure of the likelihood a person will employ the application (Fishbein et al. 1980).

In the last decades, the TAM has been widely employed in various contexts. Herrero and San Martín (2012) adopted this model to investigate the intention to use the websites of rural tourism accommodations to look for information and make online reservations. TAM has also been adopted also to identify factors for using augmented reality (AR) in heritage destinations and investigate their influence on users' attitudes and intention to use this technology and visit a destination (Chung et al. 2015). Kuo et al. (2019) associated TAM factors to E-Servicescape Environment and E-Word-of Mouth Communication, to determine user intention and willingness to use and adopt tourism apps and visit a destination. 
ToSEE - Tourism in Southern and Eastern Europe, Vol. 6, pp. 229-245, 2021.

C. Ferrara et al.: ICTS AND MOBILE APPLICATIONS FOR PROMOTING TOURISM ...

\section{THE CASE STUDY: SMART MARCA APP}

Smart Marca is a smartphone mobile application. Its aim is to promote Fermo Area as a tourism destination, by focusing on its cultural heritage and introducing digital systems as a support for managers and users. The name comes to the "Marca Fermana", the ancient administrative sub-division of central Italy, corresponding to the territory which was under the jurisdiction of the town of Fermo (Ferrara et al. 2020).

As shown in figure 1, the app provides various information, travel tips and fun opportunities and supports users in each step of the travel experience, by applying geolocation systems, beacons technology, AR and VR. Geolocalisation systems permit data mining and give to the app provider the capability to analyse the visitor catchment area, the travel routes and the most frequently visited attractions. In addition, through beacon technology, users can be notified with alerts providing real-time travel information about events, currently open attractions, changes to attraction schedule, etc. Thanks to AR systems, scanning some paintings with the smartphone/tablet camera, the app provides several tags containing specific information, offering an immersive view of the artwork. Finally, VR systems, through virtual tours, give visibility to the most significant municipalities, attractions, and typical products of the Marca Fermana. With $3 \mathrm{D}$ reconstructions and sensory wheels conceived as an interactive game, the user is driven to the sensory profile discovery of some certified local products.

\section{Figure 1: ICT architecture of Smart Marca app}

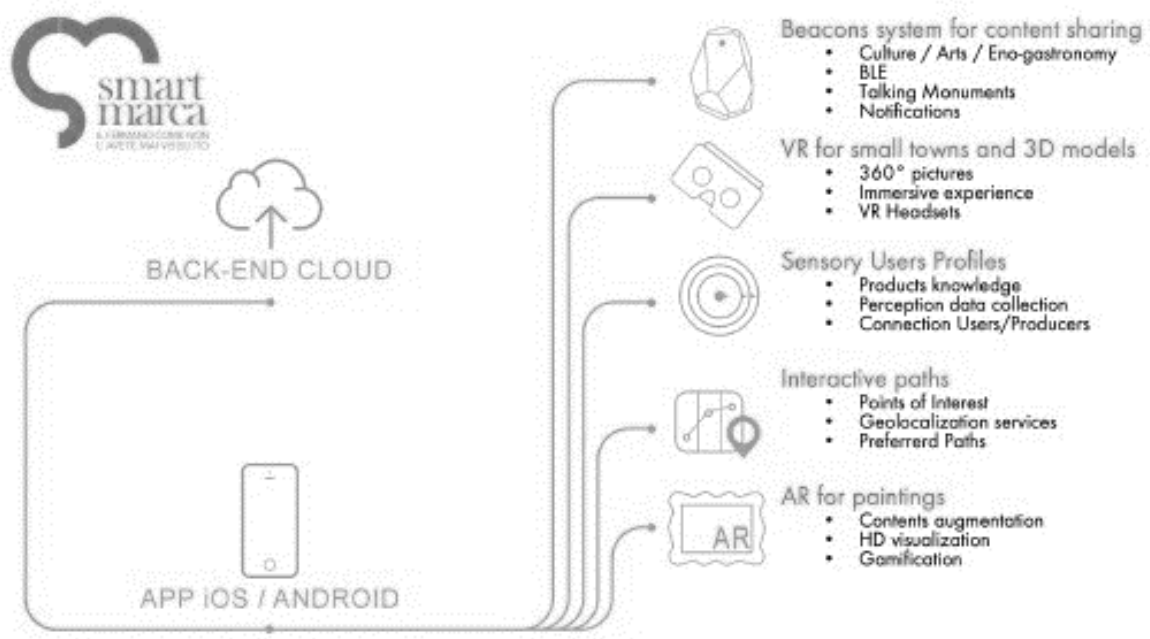

Source: Smart Marca project. 
ToSEE - Tourism in Southern and Eastern Europe, Vol. 6, pp. 229-245, 2021.

Figure 2: Smart Marca mobile app

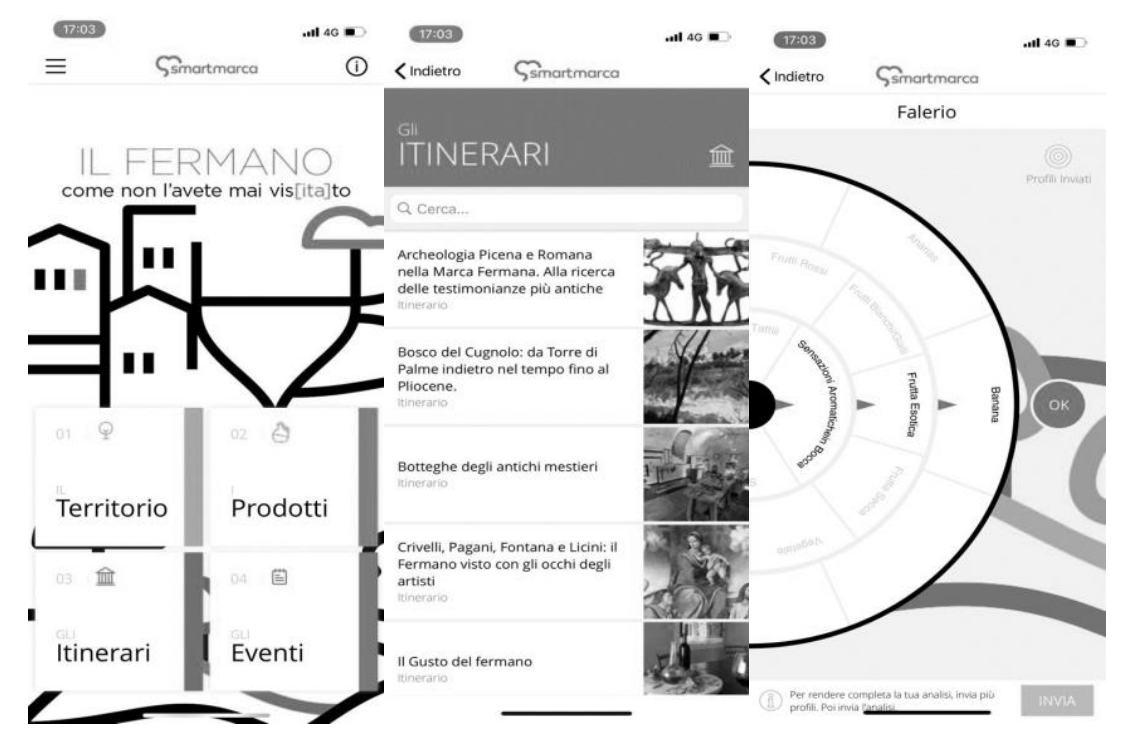

Source: Smart Marca project

\section{METHODOLOGY}

Since the use of mobile communication devices mainly affects 18-24 aged users (Blair 2019), the research focused on a sample of 128 university students attending cultural heritage and tourism courses at University of Macerata. A survey based on a questionnaire was conducted from May 2020 to March 2021 with the aim to investigate young users' attitudes towards using mobile apps for travel and tourism purposes.

The questionnaire consisted in 23 questions, aimed at collecting respondents' general information (section 1), investigating their familiarity with digital technologies (section 2) and their level of acceptance of technologies for travel and tourism purposes (section 3) and assessing users' perception about the usefulness and ease of use of the app (section 4). Sections 1-3 consisted in closed-ended questions, while section 4 included open-ended questions to assess PEU and PU also in a qualitative perspective. All respondents were asked to complete the questionnaire after they had downloaded and experienced the app.

Starting from the framework elaborated by Kuo and colleagues (2019) and considering Smart Marca app characteristics, a grid of 8 influencing factors has been built (fig. 3). TAM has been used to analyse the relationship between these 8 factors and two moderator variables, (PEU and PU), to assess their impact on users' attitudes and intentions to adopt other tourism apps, continue using Smart Marca app and visit Fermo area. To this aim, 6 research hypotheses have been formulated:

- Smart Marca characteristics have effect on PU (H.1)

- Smart Marca characteristics have effect on PEU (H.2) 
ToSEE - Tourism in Southern and Eastern Europe, Vol. 6, pp. 229-245, 2021.

C. Ferrara et al.: ICTS AND MOBILE APPLICATIONS FOR PROMOTING TOURISM

- Smart Marca characteristics have (positively) effect on attitudes towards continuing using the app $(H .3)$

- Smart Marca characteristics have (positively) effect on the intention to adopt other tourism apps (H.4).

- Smart Marca characteristics have (positively) effect on the intention to visit Fermo area and attractions included within the app (H.5)

- Attitudes towards continuing using Smart Marca positively affect the intention to visit Fermo area and attractions included within the app (H.6)

Considering these hypotheses and using a five-point Likert scale ranging from 1 (strongly disagree) to 5 (strongly agree), the questionnaire assessed respondents' levels of agreement or disagreement with 8 constructs and analysed, for each item, their influence on 3 intentions/attitudes (fig. 3).

Figure 3: Methodological framework

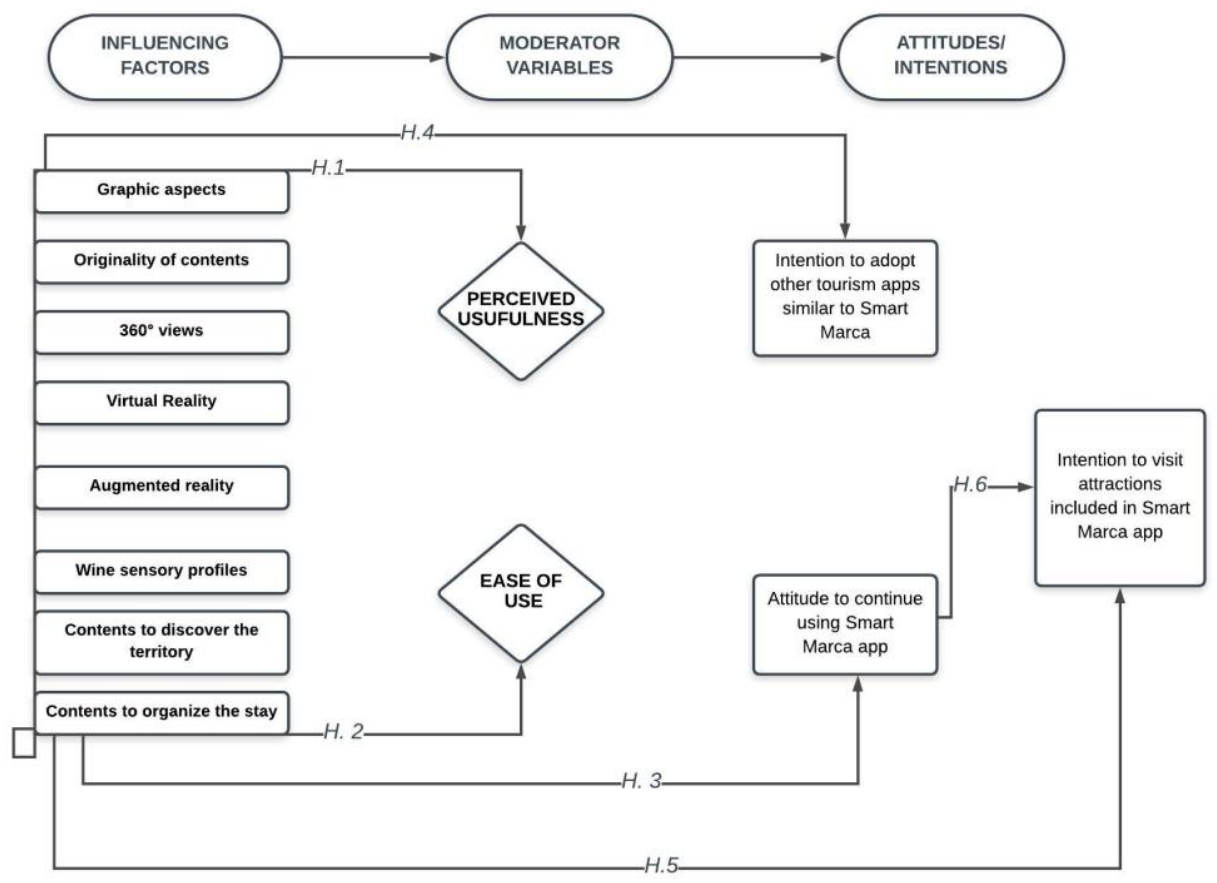

Source: authors 'elaboration

\section{FINDINGS AND DISCUSSION}

Concerning the respondents' profile, the $25 \%$ was male and the $75 \%$ female, with and average age of 22,9 . The $80 \%$ attends a bachelor's degree course in Cultural Heritage and Tourism and the $20 \%$ attend an international master's degree course in International 
ToSEE - Tourism in Southern and Eastern Europe, Vol. 6, pp. 229-245, 2021.

C. Ferrara et al.: ICTS AND MOBILE APPLICATIONS FOR PROMOTING TOURISM ...

Tourism and Destination Management. Most respondents are from Marche Region (69\%), followed by respondents from other Italian regions (25\%) and other countries (6\%).

As for their level of familiarity with technologies, the $65 \%$ of respondents declared to be familiar with digital technologies, mainly used for education and training, economy and shopping and data and telecommunication. Regarding the use of technology for travel purposes, most respondents generally use mobile app for tourism purposes in general and to enhance the knowledge of a place.

Table 2: Users' acceptance of mobile apps for tourism purposes

\begin{tabular}{|c|c|c|c|c|c|c|}
\hline \multirow[t]{2}{*}{ Influencing factors } & \multicolumn{2}{|c|}{$\begin{array}{l}\text { Your intention to } \\
\text { continue to use Smart } \\
\text { Marca app would be } \\
\text { positively affected by: }\end{array}$} & \multicolumn{2}{|c|}{$\begin{array}{c}\text { Your intention to } \\
\text { download and adopt } \\
\text { other tourism apps } \\
\text { would be positively } \\
\text { affected by: }\end{array}$} & \multicolumn{2}{|c|}{$\begin{array}{l}\text { Your intention to visit } \\
\text { attractions presented in } \\
\text { the app would be } \\
\text { positively affected by: }\end{array}$} \\
\hline & Mean & $\begin{array}{l}\text { Standard } \\
\text { deviation }\end{array}$ & Mean & $\begin{array}{l}\text { Standard } \\
\text { deviation }\end{array}$ & Mean & $\begin{array}{l}\text { Standard } \\
\text { deviation }\end{array}$ \\
\hline Graphic aspects & 2,875 & 0,83 & 3 & 0,77 & 2,82 & 0,74 \\
\hline $\begin{array}{l}\text { Contents to discover } \\
\text { the territory }\end{array}$ & 3,54 & 0,55 & 3,57 & 0,55 & 3,47 & 0,57 \\
\hline $\begin{array}{l}\text { Contents to organize } \\
\text { the stay }\end{array}$ & 3,33 & 0,74 & 3,54 & 0,6 & 3,42 & 0,66 \\
\hline $\begin{array}{l}\text { Originality of } \\
\text { contents }\end{array}$ & 3,19 & 0,8 & 3,28 & 0,79 & 3,17 & 0,82 \\
\hline $360^{\circ}$ views & 2,72 & 0,89 & 2,69 & 0,85 & 2,75 & 0,92 \\
\hline Virtual reality & 2,67 & 0,91 & 2,65 & 0,91 & 2,68 & 0,91 \\
\hline Augmented reality & 2,73 & 0,88 & 2,66 & 0,82 & 2,64 & 0,9 \\
\hline $\begin{array}{l}\text { Wine sensory } \\
\text { profile }\end{array}$ & 2,88 & 0,91 & 2,79 & 0,87 & 2,86 & 0,91 \\
\hline
\end{tabular}

Source: authors 'elaboration

As for consumers acceptance of mobile app for tourism purposes, results show that the intention to continue to use Smart Marca, adopt other tourism apps and visit places and attractions included within the app are mainly influenced by the usefulness (contents to discover the territory; contents to organize the stay) and the originality of information provided (tab 2). Graphic aspects play a major role in influencing the adoption of other tourism apps, rather than in creating a loyalty relationship in the use of Smart Marca or in triggering the decision to visit Fermo area (tab 2). The importance given to the originality of contents is also confirmed by the role attributed to VR and AR tools and to the sensory wheel: even if respondents recognized a good level of influence of these factors in all the 3 proposed scenarios, $360^{\circ}$ views and VR play a major role in influencing the decision to visit Fermo area, while AR and wine sensory profiles seem to incentive the continuing use of the app ( $\operatorname{tab} 2)$. 
ToSEE - Tourism in Southern and Eastern Europe, Vol. 6, pp. 229-245, 2021.

C. Ferrara et al.: ICTS AND MOBILE APPLICATIONS FOR PROMOTING TOURISM ...

Table 3: Users 'acceptance of mobile apps for tourism purposes. Correlation analysis

\begin{tabular}{lccc}
\hline Influencing factors & $\begin{array}{c}\text { Intention to continue to } \\
\text { use Smart Marca app } \\
\text { /attitude towards tourism } \\
\text { apps use (corr.1) }\end{array}$ & $\begin{array}{c}\text { Intention to continue } \\
\text { to use Smart Marca } \\
\text { app /intention to } \\
\text { visit Fermo area } \\
\text { (corr.2) }\end{array}$ & $\begin{array}{c}\text { Attitude towards tourism } \\
\text { apps use/ intention to } \\
\text { visit Fermo area } \\
\text { (corr.3) }\end{array}$ \\
\cline { 2 - 4 } & r value & r value & r value \\
\hline Graphic aspects & 0,161 & 0,015 & 0.484 \\
Contents to discover & 0,112 & 0,014 & 0,547 \\
the territory & 0,026 & 0,029 & 0,546 \\
Contents to organize & 0,009 & 0,632 & 0,632 \\
the stay & 0,012 & $-0,043$ & 0,763 \\
Originality of contents & $-0,071$ & $-0,121$ & 0,762 \\
$360^{\circ}$ views & 0,004 & $-0,067$ & 0,810 \\
Virtual reality & $-0,077$ & $-0,091$ & 0,794 \\
Augmented reality & & & \\
Wine sensory profile & & & \\
\hline
\end{tabular}

Source: authors 'elaboratio.

As regard for the single influence of Smart Marca characteristics on users' attitudes and intentions, the results of correlation analysis (Rosenthal and Rosnow 2008; Lazar et al. 2017) shown in table 3 suggests that the intention to continue using the app is correlated with the intention to visit Fermo area (corr. 2) as for the originality of contents provided (Pearson's r value $=0,63$ ). Virtual and augmented reality contents, as well as wine sensory profile positively affect the correlation between the attitude in using tourism apps and the intention to visit Fermo area (corr.3). Indeed, table 3 shows a positive linear relationship between the two variables, for all influencing factors, with a significative correlation in case of augmented reality $(r=0,81), 360^{\circ}$ views $(r=0,763)$, wine sensory profiles $(r=0,79)$, and virtual reality $(\mathrm{r}=0762)$.

These aspects are also confirmed by the results of the last part of the questionnaire aimed at exploring the nature of usefulness and ease of use as moderator variable in the decision to adopt a mobile app for tourism purposes. Most respondents (102) declared they had not faced usability issues and appreciated app's design and functionalities («overall the application is well designed»; «it works well»). They also specified that the app was clear, intuitive, and easy to use («it is easy to find information for short period of time»; «there are useful information which are easy to reach»; «well organized and complete information»; «usability is great, really easy to use it and to find all the information needed»). As for usefulness, most respondents declared to have downloaded the app to get a better knowledge of the territory and to discover new places («my aim was to get to know the Fermo area in greater depth»; «I wanted to discover new things to visit») and local products («I set out to analyse the wine section»). Among them, some respondents focused on the opportunity to virtually experience a place that cannot be physically visited («I would have liked to take a virtual tour of the countries that I cannot physically visit now»; «my aim was to get to know the inland villages of Marca Fermana while sitting comfortably on my sofa»). This has been considered relevant also to have a stimulus to visit the area («the aim was to find the motivation to convince me to visit the area»; «I wanted to be encouraged to visit the area»). Other respondents downloaded the app to receive 
ToSEE - Tourism in Southern and Eastern Europe, Vol. 6, pp. 229-245, 2021.

C. Ferrara et al.: ICTS AND MOBILE APPLICATIONS FOR PROMOTING TOURISM

information about facilities, restaurants, museums and their opening hours to organize a stay («my first goal would be helping me into finding the perfect places where to eat, or to stay»; «I wanted to check if it was possible to find out the opening hours of historical and archaeological sites in the Fermo area») but also to be aware about events and experiences («by using the app I wanted to find out what it could offer in terms of services and experiences»; «I downloaded it to be informed about events in the area»).

Moving from expectations to users' satisfaction, most respondents declared that the app helped them in achieving their goal, in terms of knowledge of the territory («the app introduced me to products and events that I was previously unaware of»; «I was able to easily find a large number of itineraries») and practical information («the app provided information about the opening hours of the sites I was interested in»; «in some cases this application is very useful for having practical information about towns that are in the province of Fermo»). As for the answers to the question "Which features of the app are most/least important to you?", the knowledge of the territory has been considered as the most important feature (52 responses): among the app sections, the ones focused on events, itineraries and local products have been mostly appreciated. Respondents also appreciated VR and AR tools (7), the wine sensory wheel (5) and geo-localised information (5). Speed and ease of use has been considered as important by 10 respondents, while graphics aspects and specifically the opportunity to see places, attractions and products has been considered as important by 7 respondents.

The survey found that Smart Marca characteristics firstly have effect on the level of PU (H.1) and PEU (H.2). Moreover, attitudes towards continuing using the app affected by the combination among influencing factors and moderator variables, play a specific role in influencing the intention to visit Fermo area and its attractions (H.6). Indeed, Smart Marca app has been considered as a useful tool to experience Fermo area at distance and as a stimulus/motivation to physically visit it. The stronger importance given to usefulness of contents, rather than graphic aspects and opportunities to live an immersive experience, shows that new technologies have a vital role to play in meeting the concrete needs of users in planning a trip and not just for their own sake, such as gaming or augmented reality. This is confirmed by two aspects:

- the originality of contents represents a crucial junction, in terms of scores received (tab 2), between the importance given to contents and their presentation (contents to discover the territory, contents to organize the stay, graphic aspects) and to the opportunities provided by new technologies $\left(360^{\circ}\right.$ views, virtual reality, augmented reality, wine sensory profile).

- the wine sensory wheel and AR and VR tools have been considered as important features of the app.

In this sense, Smart Marca characteristics meet 3 levels of needs and provides specific implications in terms of acceptance of mobile apps for tourism purposes:

1. they simplify the use of the app, influencing the attitude to continue using it.

2. they provide original and useful contents, influencing the attitude to adopt other mobile apps.

3. they provide and immersive experience of the territory influencing the intention to visit the destination. 
ToSEE - Tourism in Southern and Eastern Europe, Vol. 6, pp. 229-245, 2021.

C. Ferrara et al.: ICTS AND MOBILE APPLICATIONS FOR PROMOTING TOURISM ...

\section{CONCLUSION}

This study explores the connections among tourism, cultural heritage, and ICT, by investigating how customers use tourism mobile apps and how tourism apps can influence the intentions to visit a cultural destination. To this aim, potentials of e-tourism and tourism apps to promote a destination are highlighted and Smart Marca app is presented as a case study.

A survey conducted on a sample of 128 university students who used Smart Marca app and based on TAM showed that the combination of ICT and tourism is able to make a travel experience more attractive and engaging not only during and after the trip, but also remotely (Bethapudi 2013; Rezaei et al. 2016; Pierdicca et al. 2019).

Therefore, the research highlights that many factors can determine the acceptance of mobile apps for tourism purposes. First of all, users accept tourism apps because they are more inclined to accept them if they are perceived as useful and easy to use (Chung et al. 2015; Kuo et al. 2019). In this study, PU and PEU had a major role in determining attitudes towards continuing to use the app and adopting other similar apps, even they demonstrate a relevant role also in influencing the intention to visit a destination.

Consumer acceptance also depends on specific characteristics of the mobile app, mainly contents to discover the territory and organize the stay in the area (Trakulmaykee et al. 2013; Lamsfus et al. 2013), but also graphic aspects, who determine the attitude towards continuing using the app and adopting other tourism app, but also influence the intention to visit the destination experienced in a virtual way. In this sense the way how contents are provided (originality of contents), represents a relevant link between the importance given to contents (contents to discover the territory, contents to organize the stay, graphic aspects) and opportunities provided by new technologies $\left(360^{\circ}\right.$ views, virtual reality, augmented reality, wine sensory profile) to live interactive and immersive experiences (Ukpabi and Karjaluoto 2017; Osaba et al. 2018).

Moreover, the study shows that mobile travel apps can play a crucial role for the creation and promotion of a cultural destination, since they impact on the way how culture is experienced (Arcese et al. 2011; Haydar et al. 2011; Bekele et al. 2018). In this sense, if culture can be considered as a "destination enhancer", since it can positively affect the desirability of a place (Zeppel and Hall 1991; Kumar 2017) and stimulating the economic growth of a territory by attracting tourists (Silberberg 1995; Csapo 2012), technology, when applied to the promotion of a cultural destination, can act as a "destination attractor".

As for further contributions, the research also highlights that, since new technologies, and specifically tourism apps, help in analysing and understanding users' behaviours, attitudes, and intentions (Zhang et al. 2010; Önder et al. 2016), they can support mobile app providers, but also local authorities and destination management organizations (DMOs) in attracting tourists in a destination. Indeed, in a managerial perspective, the analysis of the influence of mobile tourism app on the decision to visit a destination could allow to improve contents, information, and specific other tools and furthermore segment users, supporting the definition of new ways to develop tourism marketing strategies, attract customers and improve their experience (Kounavis et al. 2012). 
ToSEE - Tourism in Southern and Eastern Europe, Vol. 6, pp. 229-245, 2021.

C. Ferrara et al.: ICTS AND MOBILE APPLICATIONS FOR PROMOTING TOURISM ...

The main limitation of this study is that the developed scale should be checked against a more differentiated sample, by considering other clusters of users and assessing their level of acceptance of a tourism mobile app like Smart Marca. Therefore, future research should apply the scale in wider and more diverse contexts to identify the impacts of perception and behaviours regarding tourism apps' consumption value on customers who use the apps.

\section{REFERENCES}

Arcese, G., Di Pietro, L. and Guglielmetti, R. (2011), "The augmented reality in the cultural heritage sector", in Proceedings of the OMOD Conference on Quality and Service Sciences.

Azuma, R., Baillot, Y., Behringer, R., Feiner, S., Julier, S., and MacIntyre, B. (2001), "Recent advances in augmented reality", IEEE computer graphics and applications, Vol. 21, No. 6, pp. 34-47. https://doi.org/10.1109/38.963459

Bandura, A. (2001), "Social cognitive theory: An agentic perspective", Annual review of psychology, Vol. 52, No. 1, pp. 1-26. https://doi.org/10.1146/annurev.psych.52.1.1

Bec A., Moyle, B., Timms, K., Schaffer, V., Skavronskaya, L. and Little, C. (2019), "Management of immersive heritage tourism experiences: A conceptual model", Tourism Management, No. 72, pp. 117-120. https://doi.org/10.1016/j.tourman.2018.10.033

Bekele, M.K. and Champion, E. (2019), "A Comparison of Immersive Realities and Interaction Methods Cultural Learning in Virtual Heritage”, Frontiers in Robotics and AI, Vol. 6, No. 91, pp. 1-14. https://doi.org/10.3389/frobt.2019.00091

Bekele, M.K., Pierdicca, R., Frontoni, E., Malinverni, E.S. and Gain, J. (2018), "A survey of augmented, virtual, and mixed reality for cultural heritage", Journal on Computing and Cultural Heritage, Vol. 11, No. 2, pp. 1-36. https://doi.org/10.1145/3145534

Bethapudi, A. (2013), "The role of ICT in tourism industry", Journal of applied economics and business, Vol. 1, No. 4, pp. 67-79.

Beverland, M. and Farrekky, F. (2010), “The quest for Authenticity in Consumption: consumers'purposive choice of authentic cues to shape experienced outcomes", Journal of consumer research, Vol. 36 , No. 5, pp. 838-856. https://doi.org/10.1086/615047

Blair, I. (2019), Mobile app download and usage statistics (2019), viewed 18 May 2021, https://buildfire.com/app-statistics/

Bogicevic, V., Seo, S., Kandampully, J.A., Liu, S.Q. and Rudd, N.A. (2019), "Virtual reality presence as a preamble of tourism experience: The role of mental imagery", Tourism Management, No. 74, pp. 55-64. https://doi.org/10.1016/j.tourman.2019.02.009

Book, L.A. and Tanford, S. (2019), "Measuring social influence from online traveler reviews", Journal of Hospitality and Tourism Insights, Vol. 3, No. 1, pp. 54-72. https://doi.org/10.1108/JHTI-06-20190080

Buhalis, D. and Jun, S.H. (2011), E-tourism. Contemporary tourism reviews, Goodfellow Publishers, Oxford.

Buhalis, D. and O'Connor, P. (2005), "Information communication technology revolutionizing tourism", Tourism recreation research, Vol. 30, No. 3, pp. 7-16. https://doi.org/10.1080/02508281.2005.11081482

Cardoso, J. and Lange, C. (2007), "A framework for assessing strategies and technologies for dynamic packaging applications in e-tourism", Information Technology Tourism, Vol. 9, No. 1, pp. 27-44. https://doi.org/10.3727/109830507779637585

Chang, I.C., Chou, P.C., Yeh, R.K.J. and Tseng, H.T. (2016), “Factors influencing Chinese tourists' intentions to use the Taiwan Medical Travel App", Telematics and Informatics, Vol. 33, No. 2, pp. 401-409. https://doi.org/10.1016/j.tele.2015.09.007

Chang, S.E. and Jang, Y.T.J. (2014), "Tourism goes mobile: A study on young and literate mobile users' adoption of smartphone enabled tourism product booking services", Journal of Applied Science and Engineering, Vol. 17, No. 1, pp. 59-72. https://doi.org/10.6180/jase.2014.17.1.08

Chung, N., Han, H. and Joun, Y. (2015), "Tourists' intention to visit a destination: The role of augmented reality (AR) application for a heritage site", Computers in Human Behavior, No. 50, pp. 588-599. https://doi.org/10.1016/j.chb.2015.02.068

Council of Europe (2015), Framework Convention on the Value of Cultural Heritage for Society, Council of Europe Treaty Series-No. 199, Faro, 27 October 2005, viewed 18 May 2021, https://rm.coe.int/1680083746 
ToSEE - Tourism in Southern and Eastern Europe, Vol. 6, pp. 229-245, 2021.

C. Ferrara et al.: ICTS AND MOBILE APPLICATIONS FOR PROMOTING TOURISM

Creagh, H. (2003, September), "Cave automatic virtual environment”, in Proceedings: electrical insulation conference and electrical manufacturing and coil winding technology conference, pp. 499-504. https://doi.org/10.1109/EICEMC.2003.1247937

Csapo. J. (2012), "The role and importance of cultural tourism in modern tourism industry, in Kasimoglu, M (Eds), Strategies for tourism industry-micro and macro perspectives, BoD-Books on Demand, $\mathrm{pp}$. 201-232.

Davis, F.D. (1985), A technology acceptance model for empirically testing new end-user information systems. theory and results (Doctoral dissertation), Massachusetts Institute of Technology.

Davis, F.D., Bagozzi, R.P. and Warshaw, P.R. (1989), "User acceptance of computer technology: A comparison of two theoretical models", Management science, Vol. 35, No. 8, pp. 982-1003. https://doi.org/10.1287/mnsc.35.8.982

European Commission (2010), Communication from the Commission to the European Parliament, the Council, the European Economic and Social Committee and the Committee of the Regions - Europe, the world's No 1 tourist destination - a new political framework for tourism in Europe, Brussels, Belgium, viewed 18 May 2021, https://eur-lex.europa.eu/legal-content/EN/TXT/PDF/ ?uri=CELEX:52010DC0352\& from=EN

Eurostat (2016), Statistics on ICT use in tourism, viewed 19 June 2021, https://ec.europa.eu/eurostat/statisticsexplained/index.php?title=Archive:Statistics_on_ICT_use_in_tourism\&oldid=420578\#Majority_o f_tourist_accommodation_is_booked_online

Ferrara, C., Pierdicca, R., Paolanti, M., Aleffi, C., Tomasi, S., Paviotti, G., Passarini, P., Mignani, C., Ferrara, A., Cavicchi, A. and Frontoni, E. (2020), "The role of ICTs and public-private cooperation for cultural heritage tourism. The case of Smart Marca", Il Capitale Culturale. Studies on the Value of Cultural Heritage, No. 10, pp. 189-204. http://dx.doi.org/10.13138/2039-2362/2424

Fishbein, M., Jaccard, J., Davidson, A.R., Ajzen, I. and Loken, B. (1980), "Predicting and understanding family planning behaviors", in Ajzen, I. and Fishbein, M. (Eds.), Understanding attitudes and predicting social behavior, Prentice Hall.

Fodor, O. and Werthner, H. (2005), "Harmonise: a step toward an interoperable e-tourism marketplace", International Journal of Electronic Commerce, Vol. 9, No. 2, pp. 11-39. https://doi.org/10.1080/10864415.2005.11044324

Fritz F., Susperregui A. and Linaza M.T. (2005), "Enhancing cultural tourism experiences with augmented reality technologies", in 6th International Symposium on Virtual Reality, Archaeology and Cultural Heritage (VAST).

García-Crespo, A., Chamizo, J., Rivera, I., Mencke, M., Colomo-Palacios, R. and Gómez-Berbís, J.M. (2009), "SPETA: social pervasive e-tourism advisor", Telematics and Informatics, Vol. 26, No. 3, pp. 306315. https://doi.org/10.1016/j.tele.2008.11.008

Gupta, A., Dogra, N. and George, B. (2018), “What determines tourist adoption of smartphone apps?”, Journal of Hospitality and Tourism Technology, Vol. 9, No. 1, pp. 50-64. https://doi.org/10.1108/JHTT-022017-0013

Guttentag, D.A. (2010), "Virtual reality: Applications and implications for tourism", Tourism Management, Vol 31, No. 5, pp. 637-651. https://doi.org/10.1016/j.tourman.2009.07.003

Haydar, M., Roussel, D., Maïdi, M., Otmane, S. and Mallem, M. (2011), "Virtual and augmented reality for cultural computing and heritage: a case study of virtual exploration of underwater archaeological sites”, Virtual reality, Vol. 15, No. 4, pp. 311-327. https://doi.org/10.1007/s10055-010-0176-4

Herrero, Á. and San Martín, H. (2012), "Developing and testing a global model to explain the adoption of websites by users in rural tourism accommodations", International Journal of Hospitality Management, Vol. 31, No. 4, pp. 1178-1186. https://doi.org/10.1016/j.ijhm.2012.02.005

Hughes, K. and Moscardo, G. (2019), "ICT and the future of tourist management", Journal of Tourism Futures, Vol. 5, No. 3, pp. 228-240. https://doi.org/10.1108/JTF-12-2018-0072

Huh, H.J., Kim, T.T. and Law, R. (2009), “A comparison of competing theoretical models for understanding acceptance behavior of information systems in upscale hotels", International Journal of Hospitality Management, Vol. 28, No. 1, pp.121-134. https://doi.org/10.1016/j.ijhm.2008.06.004

Kajos, A. and Banyai, E. (2012), "Beyond reality: The possibilities of augmented reality in cultural and heritage tourism", in 2nd International Tourism and Sport Management Conference (Debrecen, 2012 September 5-6), Vol. 5, No. 6, pp. 120-125.

Kim, M.J., Chung, N., Lee, C. and Preis, M.W. (2015), "Motivations and use context in mobile tourism shopping: applying contingency and task-technology fit theories", International Journal of Tourism Research, No. 17, pp. 13-24. https://doi.org/10.1002/jtr.1957

Kounavis, C.D., Kasimati, A.E. and Zamani, E.D. (2012), "Enhancing the tourism experience through mobile augmented reality: Challenges and prospects", International Journal of Engineering Business Management, Vol. 4, No. 10, pp. 1-6. https://doi.org/10.5772/51644 
ToSEE - Tourism in Southern and Eastern Europe, Vol. 6, pp. 229-245, 2021.

C. Ferrara et al.: ICTS AND MOBILE APPLICATIONS FOR PROMOTING TOURISM ...

Kumar, A. (2017), "Cultural and Heritage Tourism: A Tool for Sustainable Development", Global Journal of Commerce \& Management Perspective, Vol. 6, No. 6, pp. 56-59. https://doi.org/10.24105/gjcmp.6.6.1709

Kuo, T.S., Huang, K.C., Nguyen, T.Q. and Nguyen, P.H. (2019), “Adoption of mobile applications for identifying tourism destinations by travellers: an integrative approach", Journal of Business Economics and Management, Vol. 20, No. 5, pp. 860-877. https://doi.org/10.3846/jbem.2019.10448

Lai, I.K.W. (2015), "Travelers' acceptance of an app-based mobile tour guide", Journal of Hospitality \& Tourism Research, Vol. 39, No. 3, pp. 401-432. https://doi.org/10.1177/1096348013491596

Lamsfus, C., Wang, D., Alzua-Sorzabal, A. and Xiang, Z. (2015), "Going mobile: Defining context for on-thego travelers", Journal of Travel Research, Vol. 54, No. 6, pp. 691-701. https://doi.org/10.1177/0047287514538839

Lazar, J., Feng, J. H. and Hochheiser, H. (2017), Chapter 4: Statistical analysis. Research methods in human computer interaction, 71-104.

Liarokapis, F. (2007), "An augmented reality interface for visualizing and interacting with virtual content", Virtual Reality, Vol. 11, No. 1, pp. 23-43. https://doi.org/10.1007/s10055-006-0055-1

Lu, J., Mao, Z., Wang, M., and Hu, L. (2015), "Goodbye maps, hello apps? Exploring the influential determinants of travel app adoption", Current issues in Tourism, Vol. 18, No. 11, pp. 1059-1079. https://doi.org/10.1080/13683500.2015.1043248

Manyika, J., Chui, M., Bughin, J., Dobbs, R., Bisson, P. and Marrs, A. (2013), Disruptive technologies: Advances that will transform life, business, and the global economy, 180, McKinsey Global Institute, San Francisco.

McKercher, B. and Du Cros, H. (2002), Cultural Tourism: The Partnership between Tourism and Cultural Heritage Management, Haworth Hospitality Press, New York.

Meehan, K., Lunney, T., Curran, K. and McCaughey, A. (2016), "Aggregating social media data with temporal and environmental context for recommendation in a mobile tour guide system", Journal of Hospitality and Tourism Technology, Vol. 7, No. 3, pp. 281-299. https://doi.org/10.1108/JHTT-102014-0064

Mura, P., Tavakoli, R. and Sharif, S.P. (2017), “'Authentic but not too much': exploring perceptions of authenticity of virtual tourism", Information Technology \& Tourism, Vol. 17, No. 2, pp. 145-159. https://doi.org/10.1007/s40558-016-0059-y

No, E. and Kim, J.K. (2014), "Determinants of the adoption for travel information on smartphone", International Journal of Tourism Research, Vol. 16, No. 6, pp. 534-545. https://doi.org/10.1002/jtr.1945

Nunkoo, R. and Ramkisson, H. (2013), "Travelers' e-purchase intent on tourism products and services", Journal of Hospitality Marketing \& Management, No. 22, pp. 505-529. https://doi.org/10.1080/19368623.2012.680240

Önder, I., Koerbitz, W. and Hubmann-Haidvogel, A. (2016), "Tracing tourists by their digital footprints: The case of Austria", Journal of Travel Research, Vol. 55, No. 5, pp. 566-573. https://doi.org/10.1177/0047287514563985

Osaba, E., Pierdicca, R., Malinverni, E.S., Khromova, A., Álvarez, F.J. and Bahillo, A. (2018), “A smartphonebased system for outdoor data gathering using a wireless beacon network and GPS data: From cyber spaces to senseable spaces", International Journal of Geo-Information, Vol. 7, No. 5, pp. 1-21. https://doi.org/10.3390/ijgi7050190

Parra-López, E., Bulchand-Gidumal, J., Gutiérrez-Taño, D. and Díaz-Armas, R. (2011), "Intentions to use social media in organizing and taking vacation trips", Computers in Human Behavior, Vol. 27, No. 2, pp. 640-654. https://doi.org/10.1016/j.chb.2010.05.022

Pierdicca, R., Frontoni, E., Zingaretti, P., Malinverni, E.S., Colosi, F. and Orazi, R. (2015a), "Making visible the invisible. augmented reality visualization for 3D reconstructions of archaeological sites", in De Paolis, L.T, and Mongeli, A. (Eds.), International Conference on Augmented and Virtual Reality, Springer, Cham, pp. 25-37.

Pierdicca, R., Frontoni, E., Zingaretti, P., Sturari, M., Clini, P. and Quattrini R. (2015b), “Advanced interaction with paintings by augmented reality and high-resolution visualization: a real case exhibition", in De Paolis, L.T, and Mongeli, A. (Eds.), International Conference on Augmented and Virtual Reality, Springer, Cham, pp. 38-50.

Pierdicca, R., Paolanti, M. and Frontoni, E. (2019), "eTourism: ICT and its role for tourism management", Journal of Hospitality and Tourism Technology, Vol. 10, No. 1, pp. 90-106. https://doi.org/10.1108/JHTT-07-2017-0043

Rezaei, S., Ali, F., Amin, M. and Jayashree, S. (2016), "Online impulse buying of tourism products", Journal of Hospitality and Tourism Technology, Vol. 7, No. 1, pp. 60-83. https://doi.org/10.1108/JHTT03-2015-0018 
ToSEE - Tourism in Southern and Eastern Europe, Vol. 6, pp. 229-245, 2021.

C. Ferrara et al.: ICTS AND MOBILE APPLICATIONS FOR PROMOTING TOURISM

Richards, G. (2011), “Tourism development trajectories: From culture to creativity?”, Tourism \& Management Studies, No. 6, pp. 9-15.

Richards, G. (2018), "Cultural tourism: A review of recent research and trends", Journal of Hospitality and Tourism Management, No. 36, pp. 12-21. https://doi.org/10.1016/j.jhtm.2018.03.005

Richards, G. and Wilson, J. (2007), Tourism, Creativity and Development, Routledge, London.

Sahli, A.B. and Legohérel, P. (2016). "The tourism Web acceptance model: A study of intention to book tourism products online". Journal of Vacation Marketing, Vol. 22, No. 2, pp. 179-194. https://doi.org/10.1177/1356766715607589

Rosenthal, R. and Rosnow, R.L. (2008), Essentials of behavioral research: Methods and data analysis (3rd ed.), McGraw-Hill, New York. http://dx.doi.org/10.34944/dspace/66

San Martín, H. and Herrero, Á. (2012), "Influence of the user's psychological factors on the online purchase intention in rural tourism: Integrating innovativeness to the UTAUT framework", Tourism Management, Vol. 33, No. 2, pp. 341-350. https://doi.org/10.1016/j.tourman.2011.04.003

Sebastia, L., Garcia, I., Onaindia, E. and Guzman, C. (2009), "E-Tourism: a tourist recommendation and planning application", International Journal on Artificial Intelligence Tools, Vol. 18, No. 5, pp. 717-738. https://doi.org/10.1142/S0218213009000378

Shanker, D. (2008), "ICT and Tourism: Challenges and Opportunities", in International Conference Tourism in India-Challenges Ahead, Indian Institute of Management Kozhikode, pp. 50-58.

Silberberg, T. (1995), "Cultural tourism and business opportunities for museums and heritage sites", Tourism management, Vol. 16, No. 5, pp. 361-365. https://doi.org/10.1016/0261-5177(95)00039-Q

Smirnov, A., Kashevnik, A., Ponomarev, A., Shchekotov, M. and Kulakov, K. (2015, July), “Application for e-tourism: intelligent mobile tourist guide", in 2015 IIAI 4th International Congress on Advanced Applied Informatics, pp. 40-45.

Sommer, T. (2015), Travel Apps: The World of Travel in Mobile, Infographic, viewed 18 May 2021, https://applift.com/blog/travel-apps-mobile-infographic

Steinbauer, A. and Werthner, H. (2007), "Consumer behaviour in e-tourism", in Sigala, M., Mich, L. and Murphy, J. (Eds.), Information and communication technologies in tourism, Proceedings of the International Conference in Ljubljana, Slovenia, Springer, Vienna, pp. 65-76.

Timothy, D. and Boyd, S. (2003), Heritage Tourism: Theme in Tourism, Pearson Hall, Essex.

Trakulmaykee, N., Baharudin, A.S., and Arshad, M.R.M. (2013), "Effects of mobile design quality and innovation characteristics on intention to use mobile tourism guide", International Journal of Computer Science and Engineering, Vol. 7, No. 1, pp. 1225-1229. https://doi.org/10.5281/zenodo.1088748

TripAdvisor (2016), Are you reaching the lucrative Connected Traveler?, viewed 18 May 2021, https://www.tripadvisor.com/TripAdvisorInsights/w634

Ukpabi, D.C. and Karjaluoto, H. (2017), "Consumers' acceptance of information and communications technology in tourism: A review", Telematics and Informatics, Vol. 34, No. 5, pp. 618-644. https://doi.org/10.1016/j.tele.2016.12.002

Venkatesh, V., Thong, J.Y. and Xu, X. (2012), "Consumer acceptance and use of information technology: extending the unified theory of acceptance and use of technology", MIS quarterly, Vol. 36, No. 1, pp. 157-178. https://doi.org/10.2307/41410412

Wang, D. and Fesenmaier, D. (2013), "Transforming the travel experience: the use of smartphones for travel", in Cantoni, L. and Xiang, Z. (Eds.), Information and Communication Technologies in Tourism, Springer, Berlin, pp. 58-69.

Wang, H.Y. (2011), "Exploring the factors of gastronomy blogs influencing readers' intention to taste", International Journal of Hospitality Management, Vol. 30, No. 3, pp. 503-514. https://doi.org/10.1016/j.ijhm.2010.07.009

Xia, M., Zhang, Y. and Zhang, C. (2018), “A TAM-based approach to explore the effect of online experience on destination image: A smartphone user's perspective", Journal of destination marketing \& management, No. 8, pp. 259-270. https://doi.org/10.1016/j.jdmm.2017.05.002

Zeppel, H. and Hall, C.M. (1991), "Selling art and history: Cultural heritage and tourism", Journal of Tourism Studies, Vol. 2, No. 1, pp. 29-45.

Zhang, D., Guo, B., Li, B. and Yu, Z. (2010), "Extracting social and community intelligence from digital footprints: an emerging research area", in Yu, Z., Liscano, R., Chen, G., Zhang, D. and Zhou, X. (Eds.), Ubiquitous Intelligence and Computing. UIC 2010. Lecture Notes in Computer Science, Springer, Berlin, pp. 4-18. 
ToSEE - Tourism in Southern and Eastern Europe, Vol. 6, pp. 229-245, 2021.

C. Ferrara et al.: ICTS AND MOBILE APPLICATIONS FOR PROMOTING TOURISM ...

Concetta Ferrara, PhD student in Human sciences

University of Macerara

Department of Education, Cultural Heritage and Tourism

Piazzale Bertelli, 162100 Macerata (MC), Italy

+393207172549

c.ferrara3@unimc.it

Roberto Pierdicca,

Polytechnic University of Marche, Italy

Via Brecce Bianche, 12, 60131 Ancona (AN)

+39071220 4900

r.pierdicca@univpm.it

Mattia Balestra,

Polytechnic University of Marche, Italy

Via Brecce Bianche, 12, 60131 Ancona (AN)

m.balestra@pm.univpm.it

Chiara Mignani,

University of Macerata, Italy

kiara.mig@gmail.com

Emanuele Frontoni,

Polytechnic University of Marche, Italy

Via Brecce Bianche, 12, 60131 Ancona (AN)

+390712204458

e.frontoni@univpm.it

Alessio Cavicchi,

University of Pisa, Italy

Piazzale Bertelli, 162100 Macerata (MC)

alessio.cavicchi@unimc.it 